\title{
Path Coefficient and Correlation Studies of Yield and Yield Associated Traits in Advanced Homozygous Lines of Bread Wheat Germplasm
}

\author{
Preeti Sharma*, M.C. Kamboj, Narender Singh, Mehar Chand and R.K. Yadava \\ CCS Haryana Agricultural University, Regional Research Station, Karnal-132001, \\ Haryana, India \\ *Corresponding author
}

\begin{tabular}{|c|}
\hline Keywords \\
\hline $\begin{array}{l}\text { Bread wheat, } \\
\text { correlation, Path } \\
\text { coefficient analysis, } \\
\text { Direct effect and } \\
\text { indirect effects }\end{array}$ \\
\hline Article Info \\
\hline $\begin{array}{l}\text { Accepted: } \\
\text { 04 January } 2018 \\
\text { Available Online: } \\
\text { 10 February } 2018\end{array}$ \\
\hline
\end{tabular}

A B S T R A C T
The one hundred and seventy advanced homozygous lines were undertaken for estimates of mutual correlations vis-a-vis path analysis for grain yield with ten morphological traits Coefficient of variation being in the range of 1.40- 8.34 indicated adequacy of material and the traits studied for further estimation of genetic variability parameters. Mean squares due to genotypes were highly significant for all the characters observed, indicating the presence of adequate genetic variability for all the character studied. Heritability (broad sense) estimates were quite high for grain yield per plant followed by hundred grain weight and number of effective tillers per plant. The genotypic correlation coefficient is higher in magnitude as compared to that of respective phenotypic correlation coefficient and hence indicated the strong inherent nature of the characters studied. Improvement can be realized to an extent ranging from 66 to 30 per cent for grain yield per plant, tillers per plant, hundred grain weight, and grain weight per spike. Highly significant and positive association was observed between grain weight per spike and spike weight. The high direct effects in positive direction for the dependent variable i.e., grain yield per plant was recorded for number of effective tillers per plant followed by number of grains per spike, and hundred grain weight. In general, the indirect effects of the characters towards grain yield per plant were low, but the main contributors are tillers per plant, number of grains per spike and hundred grain weight. The characters viz., number of grains per spike, hundred grain weight, number of effective tillers per plant coupled with spike weight and grain weight per spike exhibiting strong positive association with grain yield indicate that selection based on these morphological traits could definitely lead to improvement in grain yield.

\section{Introduction}

Due to its adaptation to wide agro-climatic conditions, wheat (Triticum aestivum L. em Thell) is the staple food for a large number of world population. It is the most important staple food of about two billion people (36\% of the world population) (Kumar et al., 2017). Wheat is the second most produced food among many field crops and for this the studies regarding the understanding and improvement of wheat are being conducted by the routine analysis of the genetic diversity among the genotypes and the extent of 
correlation between the morphological traits which most likely contributed towards grain yield. Grain yield is a complex trait and is highly influenced by many genetic factors and environmental fluctuations. Hence the observed variability among population or in species is due to the combination of both heredity effects of concerned genes and the effect of environment. The extent of genetic variability in particular decides the efficacy of selection. The choice of selection and breeding procedures for genetic importance of any crop is largely dependent on the knowledge of type and relative amount of genetic component in the plant materials under investigations. The analysis of genetic relationships in crop sciences serves to provide information about genetic diversity and it is an important component as it serves a platform for stratified sampling of breeding population. The variation among individuals or group of individuals or populations is studied by the process of genetic diversity and can be analyzed by a specific method or a combination of methods. It is a reputable fact that greater variability among the genotypes leads to better chance for further improvement in the crop. Hence, breeder's natural interest lies in investigating the extent of variation and the type of associations of such traits.

Recombinant inbred lines (RILs) serves as a powerful tool for genetic mapping because these have been considered as immortal populations that are most suitable even for gene tagging and preparation of molecular maps in crop plants. Therefore RILs are being developed for several quality traits by using single seed descent method particularly in case of autogamous crops like in wheat. Hence RILs are the permanent population without having any change in the genetic make-up that can be maintained for infinite period. Though genetic diversity and correlation studies in bread wheat have been widely applied yet the reports are scanty for the recombinant inbred lines (RILs) or advanced breeding lines which generally the breeders involve while planning a genetic improvement.

The genotypic association is important in determining the degree to which various yieldcontributing parameters are associated with grain yield plant (Ali et. al., 2009). Since the correlation coefficients generally show relationships among independent variables and the degree of linear relations among the variables, they could not sufficiently describe the relationship when a clear cause-result relationship was found between the variables. Therefore, the direct and indirect effects between yield and yield components should be known in breeding programs (Albayrak et. al., 2003). Correlation studies along with path analysis offers a superior understanding of the association of different characters with grain yield. Path coefficient analysis is a partial regression technique which separates the direct effects from the indirect effects through other related characters by partitioning the correlation coefficient into direct and indirect effects on yield. It is most efficient method to establish relationships among the variables that affect grain yield as it allows determination of the relative magnitude of each effect. And such information is used to sustain the high yield levels of wheat for further projections.

The present investigation was conducted with the objectives to determine the variability of traits in advanced lines derived using single seed descend approach from the population HD 2204-Redpole of bread wheat in the department by realizing the importance and need for the study of genetic diversity in advanced lines with the main objective to provide information on interrelationships of yield with some important yield components and to partition the observed genotypic correlations into their direct and indirect effects. 


\section{Materials and Methods}

\section{Experimental material}

The experimental material comprising of 170 advanced homozygous lines derived using single seed descend approach from bread wheat population HD2204-Redpole were grown in Randomized Block Design with three replications at the research farm of Department of Genetics and Plant Breeding, CCS Haryana Agricultural University, Hisar, which is geographically situated at a latitude of $29^{\circ} 10^{\prime} \mathrm{N}$ and longitude $75^{\circ} 46^{\prime} \mathrm{E}$ and altitude $215.2 \mathrm{~m}$ above main sea level and falls in semi-tropical region of Western zone of India, during rabi season of 2010-11 under normal conditions.

\section{Layout of experiment}

The advanced homozygous lines were sown in a single row plot for each genotype with four replications (5-tier for homogenesity of replication) under randomized block design. Each tier comprised 34 advanced lines under single row plot of $3 \mathrm{~m}$ length, spaced 10 and 30 $\mathrm{cm}$ as intra row and inter row, respectively. All the recommended package of practices for wheat was followed to raise a healthy crop.

\section{Generation of data}

Observations on 5 randomly selected competitive plants from each of the advanced lines in each of the replication were recorded for eleven metric traits namely days to 50 per cent heading, plant height $(\mathrm{cm})$, peduncle length $(\mathrm{cm})$, spike length $(\mathrm{cm})$, spikelets per spike, number of effective tillers per plant, spike weight $(\mathrm{g})$, weight of grains per spike $(\mathrm{g})$, number of grains per spike, hundred grain weight $(\mathrm{g})$ and yield per plant $(\mathrm{g})$. The variability present in the genotypes was estimated by simple measure viz., range, mean and standard error. Genetic and environmental variances were estimated based the model proposed by (Johnson et al., 1955). The phenotypic and genotypic variance and coefficient of variation were estimated according to the methods suggested by Burton and Devane (1953). Heritability $\left(h^{2}\right)$ in broad sense and genetic advance (GA) for selection intensity $(\mathrm{K})$ at $5 \%$ were computed using the formula adopted by Allard (1960). The correlation coefficients between all possible pairs of characters from the genotypic means by procedure of Steel and Torrie (1960) and the direct and indirect effects of the independent characters on grain yield per plot were estimated by the simultaneous solution of the formula suggested by Dewey and $\mathrm{Lu}$ (1959). Whole statistical analysis was done using SPSS software package (SPSS, 1991). In the path coefficient analysis, grain yield was taken as the result (dependent) variable while the rest of the characters were considered as casual (independent) variables.

\section{Results and Discussion}

\section{Analysis of variance}

Mean square of eleven characters from analysis of variance presented in Table 1 . ANOVA revealed that the mean squares due to genotypes were highly significant for all the characters observed, indicating the presence of adequate genetic variation among the advanced lines for all the characters recorded. The prevalence of enough genetic variability in the material under the study provides the scope for selection and further subsequent utility of the advanced lines in crop improvement programme. Hence the material was appropriate for further genetical analysis. Several other researchers also reported significant differences among wheat genotypes studied (Shashikala (2006), Kalimullah et al., (2012), Yahaya (2014), Kumar et al., (2015) and Kumar et al., (2017)). 
Mean, median and range for various traits

The result of overall mean and along with median, range, critical difference, standard error and coefficient of variation for each trait have been presented in Table 2. The overall mean and median for plant height was observed as 120.84 and $121.00 \mathrm{~cm}$, respectively and for peduncle length, as 49.05 and $49.35 \mathrm{~cm}$, respectively. In case of number of spikelets per spike the overall mean and median were 21.97 and 22.00, respectively, whereas for spike length as 11.52 and 11.43 $\mathrm{cm}$, respectively and for grains per spike was recorded as 45.25 and 44.00. For effective tillers per plant, the overall mean and median were indicated as 9.12 and 9.08 and for days to 50 per cent heading was recorded as 84.93 and 84.75 days, respectively. The overall mean and median for weight characters namely spike weight has been obtained as 2.76 and $2.76 \mathrm{~g}$, respectively for grain weight per spike as 2.13 and $2.09 \mathrm{~g}$, respectively, whereas in case of hundred grain weight as 17.80 and 18.16 , respectively and for grain yield per plant were found as 17.80 and $18.16 \mathrm{~g}$, respectively. Mean and median values being quite close to respective values of various traits indicate the normal distribution of the RILs in the present study and hence, representing the spectrum of variability as would have in the base population i.e $\mathrm{F}_{2}$ where the normal distribution is expected for the traits under study if they are independently inherited.

Generally, the range of variation was wide for all the characters studied. The range for the plant height has been recorded as 79.25 to $153.00 \mathrm{~cm}$ whereas for peduncle length and spike length observed to be as 32.55 to 59.85 and 8.33 to $14.95 \mathrm{~cm}$, respectively. For number of spikelets per spike, the range was found as 17.00 to 27.00 , whereas for number of grains per spike and number of effective tillers per plant has been recorded as 30.50 to
59.50 and 5.10 to 14.85 , respectively. For days to 50 per cent heading, the range was recorded as 78.75 to 95.00 days. The range for the characters viz., spike weight, grain weight per spike, hundred grain weight and grain yield per plant has been obtained as 1.87 to $4.06 \mathrm{~g}$, 1.36 to $3.18 \mathrm{~g}, 2.38$ to $5.38 \mathrm{~g}$ and 5.75 to $33.41 \mathrm{~g}$, respectively. The coefficient of variation for the traits studied being in the range of 1.40 to 8.34 indicated the adequacy of the material and traits studied for further estimation of genetic variability parameters in present investigation. Similar results were earlier recorded by Maqbool et al., (2010), Sajjad et al., (2011) and Mecha et al., (2016).

From the results it was obtained that those characters with the higher range of values were also had higher mean values and vice versa. Such considerable range of variations provided a good opportunity for yield improvement. Thus, high variability for eleven traits in 170 advanced homozygous lines used for this study implied that there was reasonably sufficient variability, which provides ample scope for selecting superior and desired genotypes by the plant breeders for further improvement.

\section{Variability components and coefficients of variation}

The presence of adequate genetic variability is essential and its consideration combined with heritability may play a significant role in analyzing the relative contributions of genetic and non-genetic factors to the total phenotypic variation in a population. Therefore, the genetic parameters were worked out separately for the characters (Table 3 ). In the present investigation the phenotypic coefficient of variation has been in general marginally higher than the respective genotypic coefficient of variation for all the traits indicating thereby that there is negligible influence on the characters by the 
environmental fluctuations. Similarly, the genotypic variances for these characters were also high indicating that the genotype could be reflected by the phenotype and the effectiveness of selection based on the phenotypic performance for these characters. Grain yield per plant depicted highest genotypic and phenotypic coefficient of variation estimates and was followed by number of effective tillers per plant, hundred grain weight, grain weight per spike, number of grains per spike and spike length. This indicated that selection may be effective based on these characters and their phenotypic expression would be good indication of the genotypic potential. The magnitude of genotypic coefficient of variation and phenotypic coefficient of variation were low for number of spikelets per spike and days to 50 per cent heading thus indicating less scope of selection as they were under the influence of environment. Earlier similar pattern of variation at genotypic and phenotypic level have been reported by Ali et al., (2008), Wani et al., (2011), Ali and Shakor (2012) and Degewione et al., (2013) (Fig. 1).

The heritability estimates in broad sense were quite high $(>80 \%)$ for all the traits except spike weight, number of grains per spike and peduncle length thus indicating the strong genetic nature for the traits. The estimates of heritability in broad sense were moderate to high for most of the characters indicating more than 0.9 as for spike length, tillers per plant, hundred grain weight and yield per plant. High heritability values for these traits indicated that the variation observed was mainly under genetic control and was less influenced by the environment and the possibility of progress from selection. Similar results were reported by Gulnaz et al., (2012); Kalimullah et al., (2012); Singh et al., (2012); Singh and Upadhyay (2013); Yahaya (2014); Desheva and Kyosev (2015) and Kyosev and Desheva (2015).
The genetic advance indicated a good scope for improvement for almost all the traits studied as revealed by the genetic advance expressed as percentage of mean.

The genetic advance in terms of per cent of mean at 1 per cent selection intensity has been indicated very high for yield per plant, and high for tillers per plant, hundred grain weight, grain weight per spike, spike weight, spike length, number of grains per spike, and moderate for plant height, peduncle length, number of spikelets per spike and low for days to 50 per cent heading. The extent of improvement to the tune of almost 30 per cent can be achieved by adopting 5 per cent selection intensity for characters viz., tillers per plant, hundred grain weight, grain weight per spike and spike weight.

For the characters viz., spike length, number of grains per spike, the scope of improvement is above 20 per cent just by applying selection intensity of 5 per cent. The scope of improvement to the extent of around 15 per cent is indicated for characters viz., plant height, peduncle length, number of spikelets per spike just by applying selection intensity of 5 per cent. Similar results were reported by Khokhar et al., (2010) and Desheva and Kyosev (2015), while in contradictory Majumder et al., (2008) reported high genetic advance for days to maturity.

The high heritability estimates coupled with high genetic advance as per cent of mean for grain yield per plant, number of effective tillers per plant, hundred grain weight, grain weight per spike, spike weight, spike length and number of grains per spike indicate that all these characters are governed by additive gene action and as such are expected to exhibit improvement for such traits by direct selection to an extent of about more than 30 per cent over and above the respective average values for these traits. 
Table.1 ANOVA for various characters in advanced lines of HD2204-Redpole population of bread wheat

\begin{tabular}{|c|c|c|c|c|}
\hline \multirow{2}{*}{$\begin{array}{l}\text { Sr. } \\
\text { No. }\end{array}$} & \multirow[t]{2}{*}{ Characters } & \multicolumn{3}{|c|}{ Mean squares } \\
\hline & & Replication 3 & Genotypes 169 & Error 507 \\
\hline 1. & Plant height (PH) & 890.53 & $660.23 * *$ & 30.25 \\
\hline 2. & No. of spikelets per spike (NSS) & 1.69 & $14.84^{* *}$ & 0.90 \\
\hline 3. & Peduncle length (PL) & 164.11 & $110.89 * *$ & 14.60 \\
\hline 4. & Spike length (SL) & 0.90 & $8.47 * *$ & 0.19 \\
\hline 5. & No. of grains per spike (NGPS) & 250.69 & $161.80 * *$ & 13.72 \\
\hline 6. & No. of effective tillers per plant (TPP) & 19.40 & $12.55^{* *}$ & 0.33 \\
\hline 7. & Days to 50 per cent heading (DH) & 19.63 & $26.78^{* *}$ & 1.42 \\
\hline 8. & Spike weight (SW) & 0.21 & $0.78 * *$ & 0.05 \\
\hline 9. & Weight of grains per spike (GWPS) & 0.13 & $0.55 * *$ & 0.03 \\
\hline 10. & Hundred grain weight (HGW) & 0.16 & $2.07 * *$ & 0.03 \\
\hline 11. & Yield per plant (YPP) & 71.80 & $134.05 * *$ & 1.17 \\
\hline
\end{tabular}

**Significant at 1 per cent level of significance

Table.2 Mean, median and range for various morphological characters in advanced lines of HD2204-Redpole population of bread wheat

\begin{tabular}{|c|c|c|c|c|c|c|c|c|}
\hline \multirow{2}{*}{$\begin{array}{l}\text { Sr. } \\
\text { No. }\end{array}$} & \multirow[t]{2}{*}{ Characters } & \multicolumn{7}{|c|}{ Parameters } \\
\hline & & Mean & Median & Range & C.V. & S.E. $( \pm)$ & C.D. $5 \%$ & C.D. $(1 \%)$ \\
\hline 1. & Plant height & 120.84 & 121.00 & $79.25-153.00$ & 4.55 & 2.75 & 7.64 & 10.05 \\
\hline 2. & No. of spikelets per spike & 21.97 & 21.98 & $17.00-27.00$ & 4.31 & 0.47 & 1.32 & 1.73 \\
\hline 3. & Peduncle length & 49.05 & 49.06 & $32.55-59.85$ & 7.79 & 1.91 & 5.31 & 6.99 \\
\hline 4. & Spike length & 11.52 & 11.43 & $8.33-14.95$ & 3.81 & 0.22 & 0.61 & 0.80 \\
\hline 5. & No. of grains per spike & 45.25 & 44.00 & $30.50-59.50$ & 8.19 & 1.85 & 5.15 & 6.77 \\
\hline 6. & No. of effective tillers per plant & 9.12 & 9.08 & $5.10-14.85$ & 6.33 & 0.29 & 0.80 & 1.05 \\
\hline 7. & Days to 50 per cent heading & 84.93 & 84.75 & $78.75-95.00$ & 1.40 & 0.60 & 1.66 & 2.17 \\
\hline 8. & Spike weight & 2.76 & 2.76 & $1.87-4.06$ & 8.34 & 0.12 & 0.32 & 0.42 \\
\hline 9. & Weight of grains per spike & 2.13 & 2.09 & $1.36-3.18$ & 8.34 & 0.09 & 0.25 & 0.32 \\
\hline 10. & Hundred grain weight & 4.15 & 4.27 & $2.38-5.38$ & 3.88 & 0.08 & 0.22 & 0.30 \\
\hline 11. & Yield per plant & 17.80 & 18.16 & 5.75- 33.41 & 6.09 & 0.54 & 1.51 & 1.99 \\
\hline
\end{tabular}

Table.3 Genetic parameters for morphological characters in advanced lines of HD2204-Redpole population of bread wheat

\begin{tabular}{|c|c|c|c|c|c|c|c|c|}
\hline \multirow{3}{*}{$\begin{array}{l}\text { Sr. } \\
\text { No. }\end{array}$} & \multirow[t]{3}{*}{ Characters } & \multicolumn{7}{|c|}{ Genetic Parameters } \\
\hline & & \multirow[t]{2}{*}{ GCV } & \multirow[t]{2}{*}{ PCV } & \multirow[t]{2}{*}{$h^{2}(b s)$} & \multicolumn{2}{|c|}{ GA } & \multicolumn{2}{|c|}{ Genetic advance as $\%$ of mean } \\
\hline & & & & & $5 \%$ & $1 \%$ & $5 \%$ & $1 \%$ \\
\hline 1. & Plant height & 10.39 & 11.34 & 0.84 & 23.68 & 30.34 & 19.60 & 25.11 \\
\hline 2. & No. of spikelets per spike & 8.49 & 9.52 & 0.80 & 3.43 & 4.39 & 15.60 & 19.99 \\
\hline 3. & Peduncle length & 10.00 & 12.67 & 0.62 & 7.97 & 10.21 & 16.25 & 20.83 \\
\hline 4. & Spike length & 12.47 & 13.04 & 0.91 & 2.83 & 3.63 & 24.58 & 31.50 \\
\hline 5. & No. of grains per spike & 13.44 & 15.74 & 0.73 & 10.70 & 13.72 & 23.66 & 30.32 \\
\hline 6. & No. of effective tillers per plant & 19.14 & 20.16 & 0.90 & 3.41 & 4.38 & 37.44 & 47.98 \\
\hline 7. & Days to 50 per cent heading & 2.96 & 3.28 & 0.82 & 4.68 & 6.00 & 5.51 & 7.07 \\
\hline 8. & Spike weight & 15.35 & 17.47 & 0.77 & 0.76 & 0.98 & 27.80 & 35.63 \\
\hline 9. & Weight of grains per spike & 16.79 & 18.75 & 0.80 & 0.66 & 0.84 & 30.98 & 39.71 \\
\hline 10. & Hundred grain weight & 17.20 & 17.63 & 0.95 & 1.43 & 1.84 & 34.57 & 44.30 \\
\hline 11. & Yield per plant & 32.38 & 32.95 & 0.96 & 11.66 & 14.95 & 65.56 & 84.02 \\
\hline
\end{tabular}


Table.4 Phenotypic (above diagonal) and genotypic (below diagonal) correlation coefficient for various traits in 170 advanced lines of HD2204-Redpole population of bread wheat.

Phenotypic correlation coefficient

\begin{tabular}{|c|c|c|c|c|c|c|c|c|c|c|c|}
\hline Characters & PH (cm) & NSS & PL (cm) & SL (cm) & NGPS & TPP & DH & SW (g) & GWPS (g) & HGW (g) & YPP (g) \\
\hline PH (cm) & & $-0.1344 *$ & $0.5313 * *$ & 0.0575 & 0.0638 & $0.1710^{*}$ & -0.0686 & -0.0077 & 0.0565 & 0.0233 & 0.0638 \\
\hline NSS & $-0.1644 *$ & & $-0.1096 *$ & 0.0824 & 0.0857 & -0.0746 & $0.2413 * *$ & 0.0506 & 0.0546 & 0.0139 & 0.0078 \\
\hline PL (cm) & $0.7436^{* *}$ & $-0.1737^{*}$ & & 0.0851 & 0.0723 & $0.1105^{*}$ & 0.0061 & 0.0366 & 0.0532 & 0.0512 & 0.0507 \\
\hline SL $(\mathrm{cm})$ & 0.0607 & 0.0885 & $0.1272 *$ & & $0.1652 *$ & -0.0849 & 0.0775 & $0.1699 *$ & $0.1474 *$ & $0.1621^{*}$ & 0.0963 \\
\hline NGPS & 0.0845 & $0.1088^{*}$ & $0.1018^{*}$ & $0.1987^{*}$ & & $0.1123 *$ & -0.0407 & 0.3870 *** & $0.3663^{* * *}$ & 0.0961 & $0.4627 * *$ \\
\hline TPP & 0.1903* & -0.0850 & $0.1724 *$ & -0.0947 & $0.1341^{*}$ & & 0.0048 & -0.0505 & 0.0363 & 0.0707 & $0.5919 * *$ \\
\hline DH & -0.0879 & $0.3066^{* *}$ & 0.0268 & 0.0879 & -0.0597 & 0.0042 & & -0.0528 & -0.0575 & -0.0630 & -0.0367 \\
\hline SW (g) & 0.0135 & 0.0719 & 0.0712 & $0.1976^{*}$ & $0.4544 * *$ & -0.0531 & -0.0714 & & $0.9107 * *$ & $0.1839 *$ & $0.2513^{* *}$ \\
\hline GWPS (g) & 0.0902 & 0.0750 & 0.0951 & 0.1690 * & $0.4219 * *$ & 0.0479 & -0.0745 & $0.8889 * *$ & & $0.2058 * *$ & $0.2658 * *$ \\
\hline HGW (g) & 0.0257 & 0.0185 & 0.0648 & $0.1788^{*}$ & $0.1234 *$ & 0.0707 & -0.0733 & $0.2145^{* *}$ & $0.2351 * *$ & & $0.4700 * *$ \\
\hline YPP (g) & 0.0668 & 0.0100 & 0.0677 & $0.1041 *$ & $0.5474 * *$ & $0.6326^{* *}$ & -0.0431 & $0.2803 * *$ & $0.2916^{* *}$ & $0.4905^{* *}$ & \\
\hline
\end{tabular}

Genotypic correlation coefficient

$*, * *$ Significant at 5 per cent and 1 per cent, respectively

$\mathrm{PH}=$ Plant height $(\mathrm{cm}) ;$ NSS = No. of spikelets per spike; PL = Peduncle length $(\mathrm{cm}) ; \mathrm{SL}=$ Length of main spike $(\mathrm{cm})$; NGPS = No. of grains per spike; TPP = Tillers per plant; DH = Days to 50 per cent heading; SW = Spike weight (g); GWPS = Grain weight per spike (g); HGW = Hundred grain weight $(\mathrm{g})$; YPP = Yield per plant $(\mathrm{g})$

Table.5 Direct (diagonal) and indirect effects of various traits on grain yield in advanced lines of HD2204-Redpole population of bread wheat

\begin{tabular}{|c|c|c|c|c|c|c|c|c|c|c|}
\hline Characters & PH (cm) & NSS & PL (cm) & SL (cm) & NGPS & TPP & DH & SW (g) & GWPS (g) & HGW (g) \\
\hline PH (cm) & -0.0051 & 0.0008 & -0.0038 & -0.0003 & -0.0004 & -0.0010 & 0.0005 & -0.0001 & -0.0005 & -0.0001 \\
\hline NSS & 0.0030 & -0.0185 & 0.0032 & -0.0016 & -0.0020 & 0.0016 & -0.0057 & -0.0013 & -0.0014 & -0.0003 \\
\hline PL $(\mathrm{cm})$ & -0.0744 & 0.0174 & -0.1000 & -0.0127 & -0.0102 & -0.0172 & -0.0027 & -0.0071 & -0.0095 & -0.0065 \\
\hline SL (cm) & 0.0005 & 0.0007 & 0.0011 & 0.0083 & 0.0017 & -0.0008 & 0.0007 & 0.0016 & 0.0014 & 0.0015 \\
\hline NGPS & 0.0350 & 0.0450 & 0.0421 & 0.0822 & 0.4139 & 0.0555 & 0.0247 & 0.1881 & 0.1746 & 0.0511 \\
\hline TPP & 0.1111 & -0.0496 & 0.1006 & -0.0553 & 0.0783 & 0.5840 & 0.0024 & -0.0310 & 0.0280 & 0.0413 \\
\hline DH & -0.0015 & 0.0053 & 0.0005 & 0.0015 & -0.0010 & 0.0001 & 0.0172 & -0.0012 & -0.0013 & -0.0013 \\
\hline SW (g) & 0.0026 & 0.0137 & 0.0136 & 0.0376 & 0.0865 & -0.0101 & -0.0136 & 0.1905 & 0.1693 & 0.0408 \\
\hline GWPS (g) & -0.0148 & -0.0123 & -0.0156 & -0.0277 & -0.0690 & -0.0078 & 0.0122 & -0.1455 & -0.1637 & -0.0385 \\
\hline HGW (g) & 0.0104 & 0.0074 & 0.0261 & 0.0720 & 0.0496 & 0.0285 & -0.0295 & 0.0863 & 0.0946 & 0.4025 \\
\hline $\begin{array}{l}\text { Genotypic correlation } \\
\text { with grain yield (g) }\end{array}$ & 0.0668 & 0.0100 & 0.0677 & 0.1041 & 0.5474 & 0.6326 & -0.0431 & 0.2803 & 0.2916 & 0.4905 \\
\hline
\end{tabular}

$\mathrm{r}^{2}=0.7918 ;$ Residual effect $=20.82 \%$

$\mathrm{PH}=$ Plant height $(\mathrm{cm}) ;$ NSS = No. of spikelets per spike; PL = Peduncle length $(\mathrm{cm}) ; \mathrm{SL}=$ Length of main spike $(\mathrm{cm}) ;$ NGPS = No. of grains per spike; TPP = Tillers per plant; $\mathrm{DH}=$ Days to 50 per cent heading; $\mathrm{SW}=$ Spike weight $(\mathrm{g})$; GWPS = Grain weight per spike $(\mathrm{g})$; HGW = Hundred grain weight $(\mathrm{g})$; YPP = Yield per plant (g) 
Fig.1 Path diagram (genotypic) for the grain yield per plant (dependent variable)

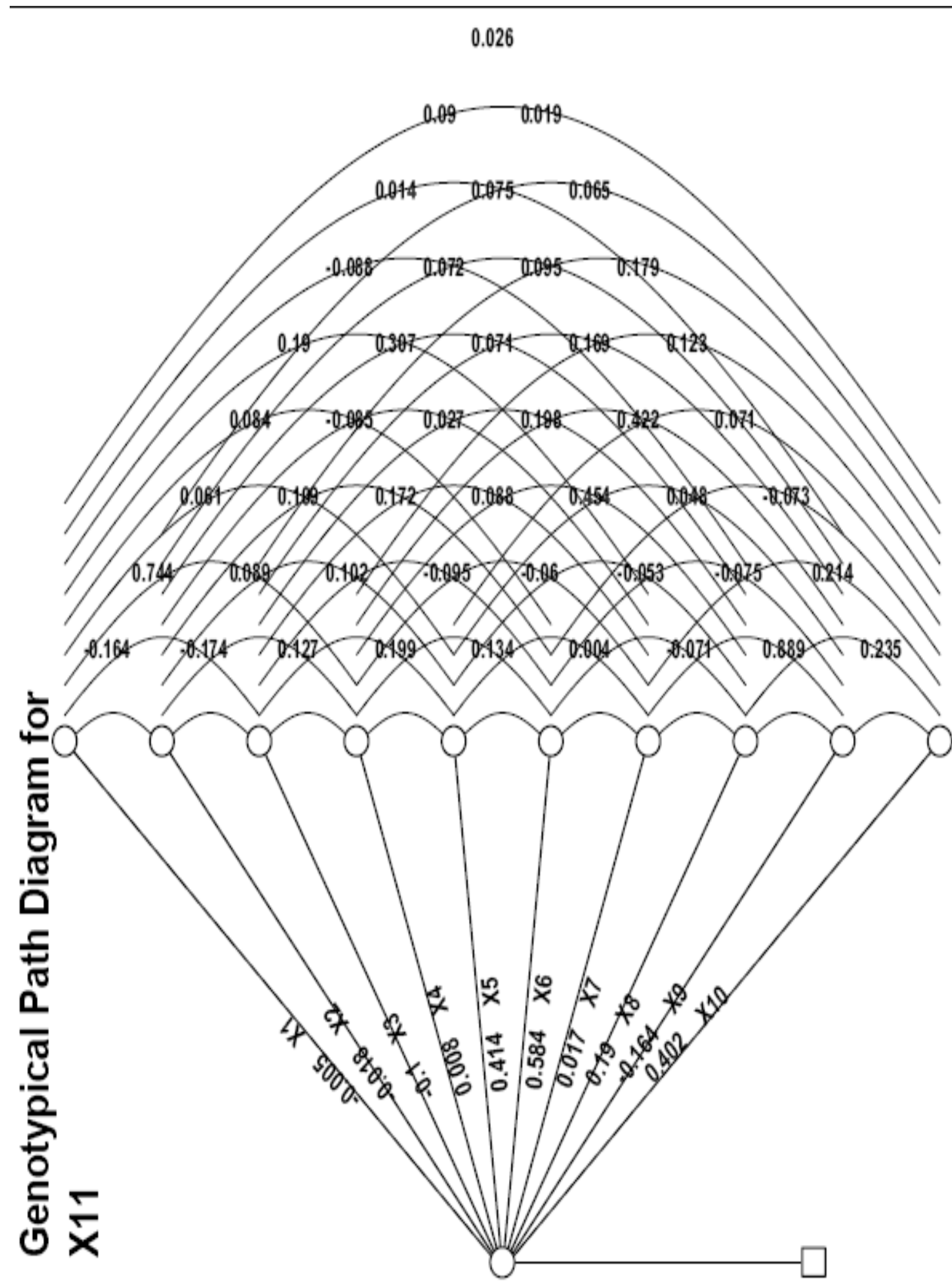

$\mathrm{X} 1=$ Plant height $(\mathrm{cm}) ; \mathrm{X} 2=$ No. of spikelets per spike; $\mathrm{X} 3=$ Peduncle length $(\mathrm{cm}) ; \mathrm{X} 4=$ Length of main spike $(\mathrm{cm}) ; \mathrm{X} 5=$ No. of grains per spike; $\mathrm{X} 6=$ Tillers per plant; $\mathrm{X} 7=$ Days to 50 per cent heading; $\mathrm{X} 8=$ Spike weight (g); X9 = Grain weight per spike (g); X10 = Hundred grain weight $(\mathrm{g}) ; \mathrm{X} 11=$ Yield per plant $(\mathrm{g})$ 
These observations are in agreement with the earlier reports of Ahmad et al., (2003); Mohammad and Khaliq (2004). Kalimullah et al., (2012); Singh and Upadhyay (2013); Yahaya (2014); Desheva and Kyosev (2015) in wheat.

\section{Correlation coefficient analysis}

The inter se correlation coefficients at phenotypic and genotypic levels depend upon the genetic makeup of the material vis-a-vis the advanced line in the form of RILs have been presented in Table 4. In majority of the cases, the genotypic correlation coefficient is higher in magnitude as compared to that of respective phenotypic correlation coefficient and hence indicated the strong inherent nature of the characters studied. These results are substantiated with those of Riaz-ud-Din et al., (2010); Ali and Shakor (2012) and Dutamo et al., (2015) in wheat. The grain yield is observed to have significant positive association with number of effective tillers per plant, number of grains per plant, hundred grain weight as expected. Grain yield per plant has further been observed to have positive association with spike weight and grain weight per spike as well. Earlier Mahmood et al., (2006), Ali et al., (2008), Riaz-ud-Din et al., (2010); Ali and Shakor (2012) and Dutamo et al., (2015) have recorded the similar pattern of significant positive correlation with grain yield. The correlation analysis indicates the departure of two characters under consideration from independence and in broader sense several coefficients may exist as measure of degree of correlation. The association between characters may be due to either linkage or pleiotropy. Hence, for executing the breeding programme efficiently, the understanding of association that exists between important characters is essential to facilitate proper interpretation of the magnitude and direction of correlation. The positive value of the correlation coefficient signify that if one trait gets larger the other will also get larger whereas the negative value denote that if one trait gets larger the other trait associated with it get smaller and it is termed as inverse correlation.

Earlier Subhani and Chowdhary (2000), Korkut et al., (2001), Ashfaq et al., (2003) and Usman et al., (2006), Ali and Shakor (2012), Kalimullah et al., (2012) and Dutamo et al., (2015) have obtained the similar pattern of association of grain yield per plant with other traits in wheat. A critical overview of Table 4 further revealed strong positive correlation coefficient for grain weight per spike with spike weight and plant height with peduncle length. The moderate correlation coefficient was obtained for number of grains per spike with spike weight and grain weight per spike and that of days to 50 per cent heading with number of spikelets per spike in the present investigation. The negative association between plant height and number of spikelets per spike and that of number of spikelets per spike with peduncle length exhibited in the present investigation is in agreement with that of the Usman, et al., (2006) in wheat. The characters exhibiting strong positive association with grain yield indicate that selection based on morphological traits could definitely lead to improvement in grain yield and therefore based on the results obtained in the present investigation it is suggested that number of grains per spike, hundred grain weight, number of effective tillers per plant coupled with spike weight and grain weight per spike be given emphasis for future improvement programme focusing on grain yield.

\section{Path coefficient analysis}

The path analysis approach provide whether the association of the independent character with the dependent one i.e grain yield in 
present case is due to its own effect or as a consequence of indirect effect via some other trait. The direct effect of the independent variable reveal a true relationship between them and the selection can be practiced for such a character in order to improve the dependent variable. However, if the association is mainly through indirect effect of the character via another attributing character for the dependent variable, then breeder may apply knowledge on that indirect effect for improving direct and dependable complex trait like grain yield.

\section{Direct effects}

A critical perusal of path coefficient analysis (Table 5) where diagonal values are direct effects, revealed that number of effective tillers per plant had highest positive direct effects on grain yield followed by number of grains per spike, hundred grain weight, spike weight, days to 50 per cent heading and spike length. Therefore, emphasis with simple selection concentrating on these traits is bound to bring improvement in grain yield which has been indicated to have high heritability coupled with high genetic advance as well. The high direct effects of the traits namely tillers per plant followed by number of grains per spike and hundred grain weight in the present investigation are in agreement with the earlier findings of Dwivedi et al., (2002), Okuyama et al., (2004) and Ali et al., (2008) and Subhashchandra et al., (2009) in wheat.

The negative direct effect towards grain yield was recorded for grain weight per spike followed by peduncle length, number of spikelets per spike and plant height.

\section{Indirect effects}

The indirect effect of the component trait towards grain yield were generally low in the present material which strongly supported the independent nature of the characters but the main contributors are tillers per plant followed by number of grains per spike and hundred grain weight. Further number of grains per spike has indirect influence for grain yield via spike weight, grain weight per spike, spike length and tillers per plant. The indirect effect for tillers per plant in positive direction towards yield per plant was observed via plant height, peduncle length, number of grains per spike and hundred grain weight. Similarly for spike weight the indirect effect in positive direction was recorded through characters viz., grain weight per spike, number of grains per spike, hundred grain weight and spike length. Positive indirect effect was also recorded for hundred grain weight via grain weight per spike, spike weight, spike length, number of grains per spike.

The negative indirect contribution towards grain yield has been mainly observed in case of grain weight per spike via spike weight. The overall picture shows that most important characters responsible for grain yield are number of effective tillers per plant, grain weight and its number per spike and hundred grain weight.

More so, in the light of the observation that plant height having positive association with peduncle length which in turn have been reported to have negative association with number of spikelets per spike and positive correlation with number of effective tillers per plant which ultimately led to the indirect effect for tillers per plant in positive direction towards grain yield per plant has been mainly exhibited via plant height and peduncle length.

This complex phenomenon can be uncurtained if emphasis is put on certain of physiological aspects as well in future studies. 


\section{References}

Ahmad, H.M., Khan, B.M., Khan, S., Kissana, N.S., and Laghari, S., 2003. Path coefficient analysis in bread wheat. Asian Journal of Plant Science. 2(6): 491-494.

Albayrak, S., Sevimay, C.S. and Töngel, M.O., 2003. Determination of characters regarding to seed yield using correlation and path analysis in inoculated and non-inoculated common vetch. Turkish Journal of Field Crops. 8(2): 76-84.

Ali, I.H. and Shakor, E.F., 2012. Heritability, variability, genetic correlation and path analysis for quantitative and traits in durum and bread wheat under dry farming. Mesoptamia Journal of Agriculture. 40(4): 27-39.

Ali, Y., Atta, B.M., Akhtar, J., Monnevux, P. and Lateef, Z., 2008. Genetic variability, association and diversity studies in wheat (Triticum aestivum L.) germplasm. Pakistan Journal of Botany. 40(5): 2087-2097.

Allard, R.W., 1960. Principles of Plant Breeding. John Wiley and Sons, New York, pp-500.

Ashfaq, M., Khan, A.S. and Ali, Z., 2003. Association of Morphological Traits with Grain Yield in Wheat. International Journal of Agriculture and Biology. 3: 262-264.

Ashfaq, M., Khan, A.S. and Ali, Z., 2003. Association of Morphological Traits with Grain Yield in Wheat. International Journal of Agriculture and Biology. 3: 262-264.

Burton, G. W. and Devane, E., H. 1953. Estimating heritability in Tall Fescue (Festuca arundinacea) from replicated clonal material. Agronomy Journal. 45: 487-488.

Desheva, G. and Kyosev, B., 2015. Genetic diversity assessment of common winter wheat (Triticum aestivum L.) genotypes. Emirates Journal of Food and Agriculture. 27(3), 283-290.

Dewey, D.R. and K.H. Lu. 1959. A correlation and path-coefficient analysis of components of crested wheatgrass grain production. Agronomy Journal. 51: 515-518.

Dutamo, D., Sentayehu, A., Firdisa, E. and Ermias, A., 2015. Path Coefficient and Correlation Studies of Yield and Yield Associated Traits in Bread Wheat (Triticum aestivum L.) Germplasm. World Applied Sciences Journal. 33 (11): 1732-1739.

Dwivedi, A.N., Pawar, I.S. and Madan, S., 2002. Studies on variability parameters and character association among yield and quality attributing traits in wheat. Haryana Agricultural University Journal of Research. 32(2): 77-80.

Gulnaz, S., Khan, S. H., Shahzad, M., Ashfaq, M. and Sajjad, M., 2012. Genetic evaluation of spring wheat (Tritium aestivum L.) germplasm for yield and seedling vigor traits. Journal of Agriculture and Social Sciences. 8: 123128.

Johnson, H. W., Robinson, H. F. and Cornstock, R. E., 1955. Estimates of genetic and environmental variability in Soybeans. Journal of Agronomy. 47: 314-318.

Kalimullah, S., Khan, J., Irfaq, M., Rahman, H. U., 2012. Genetic variability, correlation and diversity studies in bread wheat (Triticum aestivum L.) germplasm. Journal of Animal and Plant Sciences 22(2), 330-333.

Khokhar, M.I., Hussain, M. M., Zulkiffal, N., Ahmad and Sabar, W., 2010. Correlation and path analysis and for yield and yield contributing characters in wheat (Triticum aestivum L.). African Journal of Plant Science. 4(11): 464466. 
Korkut, K.Z., Baser, I. and Bilgin, O., 2001. Genotypic and phenotypic variability, heritability and phenotypic correlation for yield and yield components in bread wheat varieties. Acta Agronomica Hungarica. 49(3): 237-242.

Kumar, A., Gaurav, S.S., Kumar, A. and Rathi, V., 2017. Genetic Divergence Analysis of Agronomic Traits in Bread Wheat (Triticum aestivum L.) Genotypes. International Journal of Current Microbiology and Applied Science. 6(8): 2683-2686.

Kumar, R., Prasad, B. K., Singh, M. K., Singh, G. and Verma, A., 2015. Genetic divergence analysis for morphophysiological traits, under timely and late sown condition in bread wheat (Triticum aestivum L.). Journal of Wheat Research. 7(1):2730.

Mahmood, Q., Wu, D., Lei, A.S., Qureshi, M.R., Khan, Y., Hayat, G., Jilani, I.H., Shamsi, M.A., Tajammal and Khan, M. I., 2006. Heterosis, Correlation and Path Analysis of Morphological and Biochemical Characters in Wheat. Journal of Agriculture. 1(3): 180-185.

Majumder, D.A.N., Shamsuddin, A.K.M., Kabir, M.A. and Hassan, L., 2008. Genetic variability, correlated response and analysis of yield and yield contributing traits of spring wheat. Journal of Bangladesh Agricultural University. 6(2), 227-234.

Maqbool, R., Sajjad, M., Khaliq, I., Aziz-urRehman, Khan, A.S. and Khan, S.H. 2010. Morphological diversity and traits association in bread wheat (Triticum aestivum L.). American Eurasian Journal of Agriculture and Environmental Science. 8: 216-224.

Mecha, B., Sentayehu, A., Alemayehu, A., Ermias, A. and Dargicho, D. 2016. Genetic Variability, Heritability and Genetic Advance for Yield and Yield Related Traits in Bread Wheat (Triticum aestivum L.) genotypes. Global Journal of Science Frontier Research. 16 (7): 917.

Mohammad, K. and Khaliq, I., 2004. Heritability, correlation and path coefficient analysis for some metric traits in wheat. International Journal of Agriculture and Biology. 6(1): 138-142.

Okuyama, L.A., Federizzi, L.C. and Barbosa Neto, J.F., 2004. Correlation and path analysis of yield and its components and plant traits in wheat. Ciencia Rural. 34(6): 1701-1708.

Riaz-ud-Din, Subhani, G.M. Ahmad, N. Hussain, M. and Rehman, A.U., 2010. Effect of temperature on development and grain formation in spring wheat. Pakistan Journal of Botany. 42(2): 896899.

Sajjad, M., Khan, S.H. and Khan, A.S. 2011. Exploitation of germplasm for grain yield improvement in spring wheat (Triticum aestivum L.). International Journal of Agriculture and Biology. 13: 695-700

Shashikala, S.K., 2006. Analysis of genetic diversity in wheat. M.Sc. (Agri.) Thesis, University of Agricultural Sciences, Dharwad, India.

Singh, A. K., Singh, S. B., Singh, A. P., Sharma, A. K. 2012. Genetic variability, character association and path analysis for seed yield and its component characters in wheat (Triticum aestivum L.) under rainfed environment. Indian Journal of Agricultural Sciences. 46 (1): 48- 53.

Singh, B. and Upadhyay, P.K. 2013. Genetic Variability, Correlation and Path Analysis in Wheat (Triticum aestivum L.) Indian Research Journal of Genetics and Biotechnology. 5(3), 197-202.

SPSS, 1991. SPSS statistical algorithms $\left(2^{\text {nd }}\right.$ ed). Chicago, IL: SPSS Inc.

Steel, R. G, Torrie, J. H. and Dickey, D. A., 1997. Principles and procedures of 
statistics: A Biometrical Approach.3rd ed. McGraw Hill Book Co. New York.

Subhani, G.M. and Chowdhary, M.A., 2000. Correlation and path coefficient analysis in bread wheat under drought stress and normal conditions. Pakistan Journal of Biological Science. 3(1): 72-77.

Subhashchandra, B., Lohithaswa, H.C., Desai, S.A., Hanchinal, R.R., Kalappanavar, I.K., Math, K.K. and Salimath, P.M., 2009. Assessment of genetic variability and relationship between genetic diversity and transgressive segregation in tetraploid wheat. Karnataka Journal of Agricultural Sciences. 22 (1): 36-38.

Usman, S., Iihsan, K., Mehmood, T. and Rafique, M., 2006. Phenotypic and genotypic correlation coefficients between yield and yield components in wheat. Journal of Agricultural Research. 44(1):1-6.

Yahaya, Y. 2014. Estimate of genetic variability and correlation coefficients for some quantitative characters in bread wheat (Triticum aestivum L.). World Journal of Agricultural Sciences. 2 (7), 163-167.

\section{How to cite this article:}

Preeti Sharma, M.C. Kamboj, Narender Singh, Mehar Chand and Yadava, R.K. 2018. Path Coefficient and Correlation Studies of Yield and Yield Associated Traits in Advanced Homozygous Lines of Bread Wheat Germplasm. Int.J.Curr.Microbiol.App.Sci. 7(02): 51-63. doi: https://doi.org/10.20546/ijcmas.2018.702.008 